the age of 65 , though some kidneys from older donors have been used successfully.

Another important factor is the premortem perfusion of the kidney and the period of ischaemia after death before the kidney is removed. A kidney removed rapidly from the victim of a sudden fatal accident is likely to function much better than a kidney removed from a patient who has succumbed after a prolonged period of hypotension and shock. In these circumstances not only may the kidney have suffered tubular necrosis before it is removed, but there is a danger that the blood may be contaminated with organisms, which may be transferred with the kidney to the recipient and result in serious infection. A kidney left in a corpse for more than one hour at body temperature is also likely to suffer from severe tubular damage. This delay, often inevitable owing to the legal requirements of seeking permission for organ removal, has resulted in approximately $17 \%$ of kidneys transplanted in the United Kingdom never functioning at all. ${ }^{3}$

The Department of Health has recently issued an advisory document $^{4}$ aimed at improving the supply of kidneys for transplantation. This welcome move may help close the gap between the numbers of patients desperately needing kidney transplantation-about 2000 a year-and those actually receiving a kidney-approximately 500 a year. With better cooperation from the public and medical profession more than enough kidneys could easily be provided.

\footnotetext{
1 Tomlinson, S. A., et al., British Medical fournal, 1974, 4, 553.

2 British Medical fournal, 1975, 2, 710.

${ }^{3}$ British Transplantation Society, British Medical fournal, 1975, 1, 251.

${ }^{4}$ D.H.S.S., HSC (IS) 156, 1975.
}

\section{Prevention of Contact Dermatitis}

Contact dermatitis (eczema) is the most important form of dermatitis, requiring investigation and treatment by the family doctor, industrial medical officer, and the dermatologist. Endogenous forms such as seborrhoeic, nummular, and atopic eczema may in addition be modified by external factors, and the young atopic person in particular requires guidance on what are for him or her unsuitable occupations.

There is still no clear evidence that an atopic person is any more likely to develop contact dermatitis of the allergic type than are sufferers from other forms of endogenous eczema. ${ }^{1}$ Contact dermatitis usually results from physico-chemical damage to the skin and not from any recognizable immunological pathway. Most dermatologists would agree that an atopic person is predisposed to develop dermatitis or suffer aggravation of an already existing inflammatory reaction of the skin if he is exposed to friction, degreasing, cold, wet, and other forms of physical injury. Thus young people with atopic dermatitis require medical advice on careers early on, ${ }^{2}$ and every effort should be made to discourage them from taking up work that would entail exposure to physico-chemical injury, such as, for example, hairdressing, nursing, cooking, and certain wellrecognized parts of industry where dermatitis of the hands and arms is particularly likely to occur. The International Contact Dermatitis Research Group found that of 4000 people with contact dermatitis $68 \%$ had the hands affected, and that was the only site of the disease in about $50 \%{ }^{\circ}{ }^{1}$

This International Group, whose newsletter has recently become the journal Contact Dermatitis (No. 1 appeared in
January), has during the last few years continued to draw the attention of the medical profession, industry, and governments to the importance of contact dermatitis, the procedures which should be taken to aid diagnosis, and measures the individual and his employer can take to reduce the chances of dermatitis developing. It is doubtful if industry (either trade or profession) is in a position to select entrants on the basis of any clearly defined policy and the tendency is still to weed out the dermatitis sufferers as they occur. There are no satisfactory tests which will make this prior assessment possible. Skin tests for allergic sensitivity have no place and may even be harmful by inducing allergic sensitivity on occasions. What then to do? Perhaps we should concentrate our efforts more on the occupational hazards and their prevention. One undoubted advantage of the new National Health Service structure is the acceptance that a patient's welfare is the responsibility of the whole service. This should in time lead to quicker access from industry to the medical facilities available.

${ }^{1}$ Cronin, E., et al., Dermato-venereologica, 1970, 50, 183.

\section{Genetics of Duodenal Ulcer}

Gastric and duodenal ulcer often affect more than one member of a family. That could be due to chance coincidence, a similar response to the same environment, or a shared genetic predisposition. Family studies have shown that if several members of a family develop ulcers the ulcers tend to be of the same type, and liability to ulcer was roughly equal in members of different generations. This is modest evidence for the existence of genetic predisposition. ${ }^{12}$

Ian Aird and his colleagues found that peptic ulcer was especially frequent in people of group $\mathrm{O}^{3}$ This finding has been confirmed many times, ${ }^{4}$ and it has been expanded by the discovery that people who cannot produce their $\mathrm{ABO}(\mathrm{H})$ blood group substances in water-soluble form in their secretions are also specially liable to ulcer $^{5}$ (this characteristic is inherited independently of $\mathrm{ABO}$ blood groups). It has also been found that complications of ulcer, especially bleeding, are particularly apt to occur in people of group O. ${ }^{6} 7$ These variations are only slight, and they have been interesting more for the light they might throw on the causation of ulcer than for their clinical significance.

Lam and Sircus $^{8}$ have recently suggested that when, in patients with duodenal ulcer, the $\mathrm{ABO}$ blood groups and the secretory output of gastric acid in response to pentagastrin are considered together a consistent pattern emerges. People of group $\mathrm{O}$ tended to have a relatively low output of acid and to be prone to perforation, bleeding, and stenosis; those of groups $\mathrm{A}, \mathrm{B}$, and $\mathrm{AB}$ to be acid hypersecretors, prone to develop the disease earlier, and to have the strongest family prevalence. They further consider that separation into these two groups may help in determining the proper surgical procedure for each type of ulcer, for they suggest that the group $\mathrm{A} / \mathrm{B} / \mathrm{AB}$ hypersecretory ulcer develops on a background of parietal cell hyperplasia, while the group $\mathrm{O}$ normosecretory ulcer occurs in a patient with an overactive gastric antrum.

If the authors are correct, a number of observations need reconciling with their data. Firstly, the interrelationship of secretor status with their proposed system needs delineation. The most obvious hypothesis would be that $\mathrm{ABO}(\mathrm{H})$ nonsecretion is associated with a normal acid output, since there 